\title{
Neuronal influence behind the central nervous system regulation of the immune cells
}

\author{
Anahí Chavarría ${ }^{1 *}$ and Graciela Cárdenas ${ }^{2}$ \\ ${ }^{1}$ Laboratorio de Neuroinmunología, Departamento de Medicina Experimental, Facultad de Medicina, Universidad Nacional Autónoma de México, México City, \\ México \\ ${ }^{2}$ Departamento de Neuroinfectología, Instituto Nacional de Neurología y Neurocirugía Manuel Velasco Suárez, México City, México
}

\section{Edited by:}

Beatriz Gomez-Gonzalez,

Universidad Autonoma

Metropolitana, Mexico

Reviewed by:

Svetlana P. Chapoval, University of Maryland, USA

Peter M. Grace, University of

Colorado at Boulder, USA

\section{*Correspondence:}

Anahi Chavarría, Laboratorio de Neuroinmunología, Departamento de Medicina Experimental, Facultad de Medicina, Universidad Nacional Autónoma de México, Hospital General de México, Unidad 505, Dr. Balmis 148, Col. Doctores, CP 06726 México City, México e-mail: anahi.chavarria@gmail.com
Central nervous system (CNS) has a highly specialized microenvironment, and despite being initially considered an immune privileged site, this immune status is far from absolute because it varies with age and brain topography. The brain monitors immune responses by several means that act in parallel; one pathway involves afferent nerves (vagal nerve) and the other resident cells (neurons and glia). These cell populations exert a strong role in the regulation of the immune system, favoring an immune-modulatory environment in the CNS. Neurons control glial cell and infiltrated T-cells by contact-dependent and -independent mechanisms. Contact-dependent mechanisms are provided by several membrane immune modulating molecules such as Sema-7A, CD95L, CD22, CD200, CD47, NCAM, ICAM-5, and cadherins; which can inhibit the expression of microglial inflammatory cytokines, induce apoptosis or inactivate infiltrated T-cells. On the other hand, soluble neuronal factors like Sema-3A, cytokines, neurotrophins, neuropeptides, and neurotransmitters attenuate microglial and/or T-cell activation. In this review, we focused on all known mechanism driven only by neurons in order to control the local immune cells.

Keywords: neuronal immune modulation, central nervous system, neuron-microglia interaction, neuron-T cell interaction, CD200, neurotrophins, neurotransmitters, semaphorins

\section{INTRODUCTION}

The central nervous system (CNS) has a highly specialized immune-modulatory microenvironment, which has developed several mechanisms to protect itself from immune-mediated inflammation. This microenvironment is sustained by existing physiological and anatomical elements such as the blood-brain barrier (BBB) that limits peripheral immune cells and molecules entry; the afferent nerves of the autonomic nervous system with anti-inflammatory properties; and finally, the resident cells like astrocytes and neurons, which also contribute to the local immune privilege through the expression of anti-inflammatory suppressive factors and cell surface molecules (Carson et al., 2006).

The ability of neurons to sense changes in the brain and the body is a key factor in maintaining CNS-homeostasis. There is a large body of evidence that immune and neuronal systems communicate with each other by soluble factors as neurotransmitters, neuromodulators, and neuropeptides, or through cell-cell contact by neuroimmune regulatory molecules that can reduce or inhibit any exacerbated inflammatory response (Tian et al., 2009).

In this review, we focus on the general neuron-cell contactdependent and contact-independent mechanisms involved in the immune modulation in order to maintain CNS immune privilege, even though microglia and astrocytes constitute the first line of defense.

\section{CONTACT-DEPENDENT MECHANISM FOR IMMUNE MODULATION}

Neurons can display an array of membrane molecules in order to control local immune functions; these molecules can target local immune cells like microglia and astrocytes or peripheral immune cells present in the CNS. When BBB is ruptured, immune privilege is lost and neurons may come in contact with $\mathrm{T}$ or mononuclear cells, endangering their survival. However, neurons might modulate these immune cells by several strategies, either indirectly suppressing T-cell activation by restriction of antigen presenting properties of glial cells, directly suppressing T-cell activation, favoring a Th2 profile or promoting apoptosis of activated microglia and T-cells (Tian et al., 2009).

\section{MOLECULES INHIBITING GLIAL ACTIVATION}

The neuronal cell adhesion molecule (NCAM/CD56) is expressed on the surface of neurons, astrocytes and microglia (Sporns et al., 1995; Krushel et al., 1998; Chang et al., 2000a,b), and has a critical role in cell-cell adhesion, synaptic plasticity, neurite outgrowth, among other processes (Tian et al., 2009). Astrocyte-neuron interactions via NCAM lead to modulate glial scar formation by the inhibition of astrocyte proliferation in vitro and in vivo after performed stab lesions in the striatum, cerebral cortex, or hippocampus (Krushel et al., 1995, 1998). NCAM requires the activation of the glucocorticoid receptor to inhibit growth 
factor-induced mitogen activated protein kinase (MAPK) activity and therefore preventing astrocytic proliferation (Krushel et al., 1998). NCAM also modulates microglial activation, decreases the production of $\mathrm{TNF} \alpha$ and nitric oxide (NO) after glial stimulation with lipopolysaccharide (LPS) by reducing the expression of transcription factors like c-Jun, among others (Chang et al., 2000a,b). For the mediation of glial immune responses the homophilic binding of third Ig domain of NCAM is crucial (Sporns et al., 1995; Krushel et al., 1998).

Another important molecule thought to contribute to the constitutive anti-inflammatory and regulatory environment of the brain is CD200, a highly expressed glycoprotein in the CNS, mainly in neurons (Chitnis et al., 2007; Koning et al., 2009). Neuronal CD200 down-modulates the activation state of perivascular macrophages and microglia trough the CD200 receptor (Hoek et al., 2000). Upon binding to its ligand, the tyrosine residues on the cytoplasmic tail of CD200R are phosphorylated and the downstream signaling leads to inhibition of p38 MAPK, c-Jun N-terminal kinase (JNK), and extracellularsignal-regulated kinases (ERK; Zhang et al., 2004), interfering with the activation of macrophages and microglia. Moreover, IL4 mediated neuronal CD200 expression maintains microglia in a quiescent state and anti-inflammatory/neuroprotective profile (Lyons et al., 2009). Additionally, aging leads to a depressed CD200 expression and microglial activation, favoring a proneurodegenerative disease environment (Cox et al., 2012). Also, defects in CD200-CD200R pathway play a critical role in neurodegenerative disease development such as multiple sclerosis (MS), Parkinson's and Alzheimer's diseases (Koning et al., 2007; Walker et al., 2009; Zhang et al., 2011).

CD22 is a regulatory sialic-acid-binding molecule that mediates neuron binding to microglia through CD45, inhibiting CD40L-induced microglial activation by suppression of the p38 and p44/42 MAPK signaling pathway and preventing microglial TNF $\alpha$ production after LPS stimulation (Tan et al., 2000; Mott et al., 2004; Zhu et al., 2008).

Neuronal membrane integrin-associated protein (CD47) is specially concentrated on synapses and exerts its neuroimmune functions mainly via two receptors (Tian et al., 2009). CD172 $(\mathrm{SIRP} \alpha)$ ligation results in phosphatidylinositide 3-kinase (PI3K) signaling cascade activation, and reduces inflammation severity by increasing TGF $\beta$ levels, diminishing phagocytosis TNF $\alpha$ and INF $\alpha$ levels (Reinhold et al., 1995; Smith et al., 2003). Furthermore, decreased levels of CD47 are found in chronic active and inactive MS lesions, possibly favoring persistence of damage by the lack of regulation of activated microglia and macrophages (Koning et al., 2007). CD47 interaction with thrombospondin TSP, a further receptor, leads to T-cell and microglia apoptosis via CD95/CD95L pathway also reducing inflammation (Lamy et al., 2007).

Residential brain cells express CD95L (FasL) constitutively to limit possible damaging inflammatory responses. Neuronal CD95L expression induces apoptosis of infiltrating and autoreactive T-cells (Flügel et al., 2000), as well of activated microglia (Choi and Benveniste, 2004). Additionally, CD95L protects neurons from perforin-mediated T-cell cytotoxicity (Medana et al., 2001).
The expression of chemokine CX3CL1 (fractalkine) and its receptor CX3CR1 is limited to neurons and microglia, respectively (Hughes et al., 2002). CX3CL1 can be found membrane-anchored or secreted both in physiological and pathological conditions such as facial motor nerve axotomy or a toxic model of Parkinson's disease (Harrison et al., 1998; Cardona et al., 2006). CX3CL1-CX3CR1 interactions lead to the JNK MAPK pathway activation and Nrf2 recruitment suppressing the neurotoxic microglia activity and reducing neuronal death due to inflammation (Zujovic et al., 2000; Mizuno et al., 2003; Cardona et al., 2006; Noda et al., 2011).

\section{MOLECULES INHIBITING IMMUNE CELLS}

Plexin and semaphorin signaling has revealed that several members of this family are involved in immune cell processes. Among these semaphorins are Sema-3A, Sema-3E, Sema4D, Sema-4A, Sema-6D, and Sema-7A (Roney et al., 2013). However, only Sema-3A and Sema-7A are expressed by neurons, respectively either as secreted or membrane-bound regulatory proteins that attenuate T-cell activation, proliferation, and function through T-cell receptor (TCR) signaling (Czopik et al., 2006; Lepelletier et al., 2006). Sema-3A exerts its action forming a complex with neuropilin-1 and plexin-A1 that leads to the prevention of immune response over-activation and the inhibition of human monocytes migration through the blockage of actin cytoskeleton reorganization, interfering with TCR polarization and signal transduction events by downmodulation of MAPK signaling cascades (Lepelletier et al., 2006). Also stressed neurons may induce apoptosis of INF $\gamma$ or LPS activated microglia through Sema-3A secretion recruiting CD95 to lipid rafts next to neuropilin-1 (Majed et al., 2006; Moretti et al., 2008). Sema-7A, a glycosylphosphatidylinositollinked semaphorin, negatively regulates TCR signaling and avoids activation of the ERK-MAPK pathway decreasing T-cell

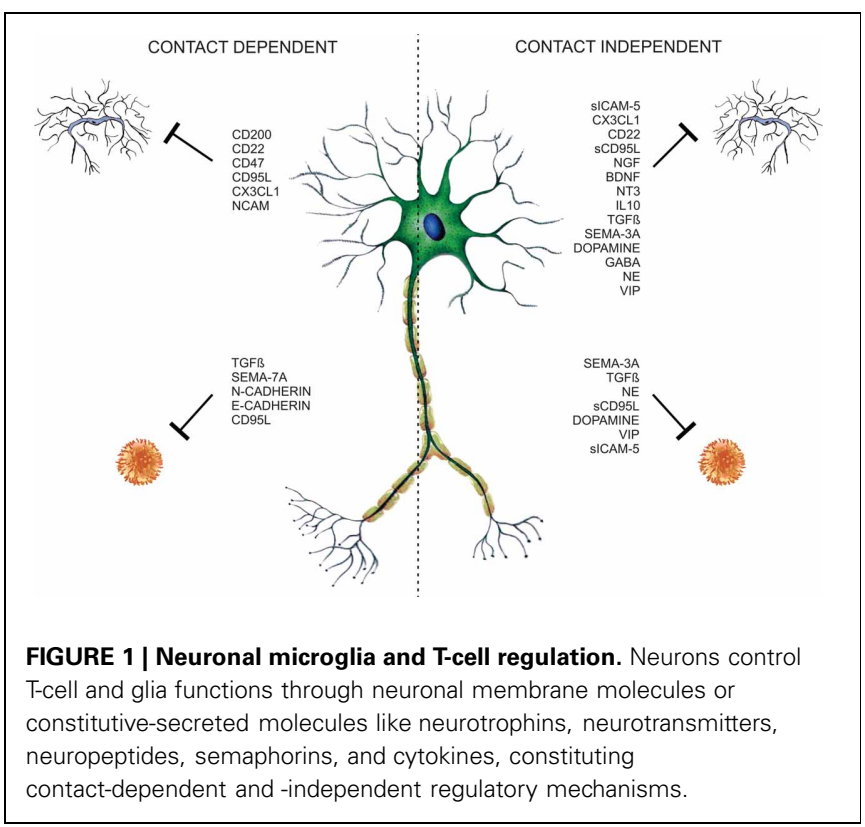


proliferation. Sema-7A deficient mice present T-cell hyperresponsiveness and hyperproliferation with severe experimental autoimmune encephalomyelitis pathology (Czopik et al., 2006).

Additionally, $\mathrm{N}$ - and E-cadherins are highly expressed in the CNS and bind to the killer cell lectin-like receptor G1 (KLRG1) on NK- and T-cells, preventing NK lysis of neurons and suppressing CD8 + T-cells antigenic proliferation and cytolytic activity (Gründemann et al., 2006; Ito et al., 2006).

Only soma and dendrites of neurons express the intercellular adhesion molecule-5 (ICAM-5/telencephalin; Tian et al., 2000). Neurons bind to T-cell through the ICAM-5-CD11a/Cd18 (LFA1) interaction diminishing TCR dependent T-cell activation and enhancing TGF $\beta$ and INF $\gamma$ expression in naïve T-cells (Tian et al., 2008). Additionally, ICAM-5 can be cleaved by activated T-cell or microglial-secreted matrix metalloproteinases- 2 and -9 , soluble ICAM-5 may compete with ICAM-1 costimulatory signal necessary for T-cell activation (Tian et al., 2008). Also, soluble ICAM-5 is present in blood and cerebrospinal fluid after hypoxia due to carotid artery ligation in mice and acute encephalitis in humans (Guo et al., 2000; Lindsberg et al., 2002). Moreover, ICAM-5 regulates microglia morphology and function by facilitating cell spreading and increasing CD11a/Cd18 expression (Mizuno et al., 1999).

\section{NEURON-MEDIATED GENERATION OF REGULATORY T-CELLS}

Regulatory T-cells (Tregs) are important in keeping CNS homeostasis in healthy and pathological conditions, and are also locally induced by glia cells and neurons (Liu et al., 2006; Saenz et al., 2010). Encephalitogenic T-cell production of IFN $\gamma$ and TNF $\alpha$ leads to neuronal expression of TGF $\beta 1, \mathrm{CD} 80$, and CD86, which induce encephalitogenic CD4 + T-cells to become Tregs, in a cell-to-cell dependent and antigen independent way through the TGF- $\beta 1-$ TGF- $\beta$ R and TCR signaling pathway (Issazadeh et al., 1998; Liu et al., 2006). Neuron-induced Tregs are able to inhibit progression of experimental autoimmune encephalomyelitis by suppression of encephalitogenic CD4 $+\mathrm{T}$-cells proliferation (Liu et al., 2006).

\section{Table 1 | Main neuronal immune regulatory molecules, their receptors and target cells in the CNS.}

\begin{tabular}{|c|c|c|c|}
\hline Neuronal molecule & Target cell & Receptor & References \\
\hline \multicolumn{4}{|c|}{ CADHERIN SUPERFAMILY } \\
\hline E-cadherin & NK-cell, T-cell & KLRG1 & Gründemann et al., 2006; Ito et al., 2006 \\
\hline \multicolumn{4}{|c|}{ IMMUNOGLOBULIN SUPERFAMILY MOLECULES } \\
\hline $\mathrm{CD} 22$ & Microglia & CD45 & Mott et al., 2004 \\
\hline ICAM-5 & T-cell & $\mathrm{CD} 11 \mathrm{a} / \mathrm{Cd} 18$ & Mizuno et al., 1999; Tian et al., 2000, 2008 \\
\hline NCAM & Microglia, Astrocyte & NCAM & Sporns et al., 1995; Krushel et al., 1998; Chang et al., 2000a \\
\hline \multicolumn{4}{|c|}{ TUMOR NECROSIS FACTOR FAMILY } \\
\hline CD95L & Microglia, T-cell & CD95 & Choi and Benveniste, 2004 \\
\hline \multicolumn{4}{|c|}{ CYTOKINES AND CHEMOKINES } \\
\hline GABA & Microglia & $\mathrm{GABA}_{A}, \mathrm{GABA} \mathrm{B}_{\mathrm{B}}$ & Färber and Kettenmann, 2005 \\
\hline Dopamine & Microglia, T-cell & $D_{1}, D_{2}, D_{3}, D_{4}, D_{5}$ & Färber et al., 2005 \\
\hline NE & Microglia, Astrocyte, T-cell & $\alpha_{1 A}, \alpha_{2 A}, \beta_{1}, \beta_{2}$ & Färber et al., 2005; Gyoneva and Traynelis, 2013 \\
\hline VIP & Astrocyte, T-cell & $\mathrm{VPAC}_{1}, \mathrm{VPAC}_{2}$ & Delgado et al., 2004, 2008 \\
\hline \multicolumn{4}{|l|}{ NEUROTROPHINS } \\
\hline NGF & Microglia, Astrocyte & p75, NTR, TrkA & $\begin{array}{l}\text { Neumann et al., 1998; Althaus and Richter-Landsberg, 2000; } \\
\text { Cragnolini et al., } 2012\end{array}$ \\
\hline BDNF & Microglia, Astrocyte & p75, NTR, TrkB & Neumann et al., 1998; Althaus and Richter-Landsberg, 2000 \\
\hline NT-3 & Microglia & p75, NTR, TrkB, TrkC & $\begin{array}{l}\text { Neumann et al., 1998; Althaus and Richter-Landsberg, 2000; } \\
\text { Tzeng and Huang, } 2003\end{array}$ \\
\hline \multicolumn{4}{|l|}{ SEMAPHORINS } \\
\hline
\end{tabular}

BDNF, brain-derived neurotrophic factor; ICAM-5, intercellular adhesion molecule-5; GABA, $\gamma$-aminobutyric acid; NCAM, neuronal cell adhesion molecule; NE, norepinephrine; NGF, nerve growth factor; NT-3, neurotrophin-3; Sema-3A, semaphorin-3A; Sema-7A, semaphorin-7A; VIP, vasoactive intestinal peptide. 


\section{CONTACT INDEPENDENT MECHANISMS FOR IMMUNE MODULATION}

Constitutive-secreted neurotrophins, neurotransmitters, and neuropeptides, as well as cytokines provide contact-independent routes for neurons to control microglial and T-cell activities.

Neurotrophins play a critical role in the control of neuronal survival, migration, and differentiation and modulate immune cell functions (Tabakman et al., 2004). Nerve growth factor (NGF), brain-derived neurotrophic factor (BDNF), and neurotrophin-3 (NT-3) can inhibit MHCII expression in microglia in hippocampal slice cultures via the low affinity p75 neurotrophin receptor (Neumann et al., 1998). NGF also down-regulates the co-stimulatory molecules CD40 and CD86 in microglia (Wei and Jonakait, 1999), is increased in cerebral spinal fluid of MS patients (Laudiero et al., 1992), and NGF treatment delays EAE onset and clinical severity (Arredondo et al., 2001). In addition, NGF arrests astrocyte cell cycle possibly restricting glial scar formation after CNS injury via the p75 neurotrophin receptor, attenuating cyclins D1 and E and preventing the degradation of cyclin-dependent kinase inhibitors p15INK and p27kip1 (Cragnolini et al., 2012). Interestingly, NT3 has anti-inflammatory properties by diminishing microglial inducible form of NO synthase, NO, IL1- $\beta$, and TNF $\alpha$ levels, and phagocytic activity after LPS stimulation. NT-3 exerts its effects mainly through the TrkC receptor leading to the activation of MAPK and PI3K cascades and decreasing the NFкB-p65 activity (Tzeng and Huang, 2003; Tzeng et al., 2005).

IL10 and TGF $\beta$ cytokines have anti-inflammatory and suppressive properties that importantly regulate CNS inflammatory responses and resident cells survival (Pratt and McPherson, 1997; Strle et al., 2001). Both cytokines and their receptors are expressed by neurons and glial cells throughout the CNS (Szelényi, 2001). These regulatory molecules down-regulate microglia inhibiting the expression of MHCII, pro-inflammatory cytokines such as TNF $\alpha$ and IL1 $\beta$, as well as NO synthesis after LPS activation (Suzumura et al., 1993; Sawada et al., 1999; Heyen et al., 2000). Furthermore, IL10 and TGF $\beta$ have an important role on Tregs and keep autoimmune T-cells under the steady state (Saenz et al., 2010).

Among the neuropeptides and neurotransmitters with modulatory properties that inhibit microglial LPS-induced proinflammatory factors like IL1 $\beta$, IL6, TNF $\alpha$, and $\mathrm{NO}$, are

\section{REFERENCES}

Althaus, H. H., and Richter-Landsberg, C. (2000). Glial cells as targets and producers of neurotrophins. Int. Rev. Cytol. 197, 203-277. doi: 10.1016/S0074-7696(00)97005-0

Arredondo, L. R., Deng, C., Ratts, R. B., Lovett-Racke, A. E., Holtzman, D. M., and Racke, M. K. (2001). Role of nerve growth factor in experimental autoimmune encephalomyelitis. Eur. J. Immunol. 31, 625-633.

Bjurstöm, H., Wang, J., Ericsson, I., Bengtsson, M., Liu, Y., Kumar-Mendu, S., et al. (2008).
GABA, a natural immunomodulator of $\mathrm{T}$ lymphocytes. J. Neuroimmunol. 205, 44-50. doi: 10.1016/j.jneuroim.2008.08.017

Cardona, A. E., Pioro, E. P., Sasse, M. E., Kostenko, V., Cardona, S. M., Dijkstra, I. M., et al. (2006). Control of microglial neurotoxicity by the fractalkine receptor. Nat. Neurosci. 9, 917-924. doi: 10.1038/ nn 1715

Carson, M. J., Doose, J. M., Melchior, B., Schmid, C. D., and Ploix, C. C. (2006). CNS immune privilege: hiding in plain sight.

vasoactive intestinal peptide (VIP), dopamine, norepinephrine $(\mathrm{NE})$, and $\gamma$-aminobutyric acid (GABA; Färber et al., 2005; Bjurstöm et al., 2008; Delgado et al., 2008). VIP exerts its anti-inflammatory effects through the $\mathrm{VPAC}_{1}$ and $\mathrm{VPAC}_{2}$ receptors inhibiting p38 and p42/p44 MAPK and NFKB signaling cascades (Delgado et al., 2008). Also, VIP treatment avoids beta-amyloid neurodegeneration and MPTP-induced dopaminergic neuronal loss (Delgado and Ganea, 2003; Delgado et al., 2008). Additionally; VIP induces protective TH2 cells by upregulation of macrophage $\mathrm{B} 7.2$ expression and Tregs in a EAE model (Delgado et al., 2004; Fernandez-Martin et al., 2006). Physiological concentrations of GABA activate functional $\mathrm{GABA}_{\mathrm{A}}$ channels on encephalitogenic T-cell decreasing cell proliferation, while $\mathrm{GABA}_{\mathrm{B}}$ channels activation on microglia attenuates IL6 and IL 12p40 levels after LPS stimulation (Kuhn et al., 2004; Bjurstöm et al., 2008). Functional dopamine receptors $D_{1}$ and $\mathrm{D}_{2}$ are expressed by microglia and their activation lead to attenuate NO production after LPS stimulation (Kuhn et al., 2004). CNS NE levels are relevant in order to maintain tissue homeostasis since NE loss contributes to neuroinflammatory processes that lead to neurodegenerative diseases, for instance depressed mice with low NE levels respond with higher TNF $\alpha$ production after LPS stimulation while increasing NE levels are necessary to reduce EAE severity (Szelényi and Vizi, 2007; Simonini et al., 2010). Moreover, NE regulates microglia morphology and motility by microglial processes retraction; in this dynamic process the $\beta 2$ and $\alpha 2 \mathrm{~A}$ receptors are involved in resting cells and activated microglia cells, respectively (Gyoneva and Traynelis, 2013).

\section{CONCLUSIONS}

Traditionally glial cells are considered to be responsible for the regulation of immune processes in the CNS. Nevertheless neurons contribute to immune modulation through contact-dependent and -independent mechanisms (Figure 1). Several neuronal secreted as well-membrane associated molecules (Table 1) are implicated in the control of glial and T-cell functions, thus contributing to CNS immune privilege.

\section{ACKNOWLEDGMENTS}

Funding was provided by the grant IN217612 from Dirección General de Asuntos del Personal Académico (DGAPA), National Autonomous University of Mexico. The authors wish to acknowledge Bernardo Pohlenz for his artwork assistance.

Immunol. Rev. 213, 48-65. doi: 10.1111/j.1600-065X.2006.00441.x

Chang, R. C., Hudson, P., Wilson, B., Haddon, L., and Hong, J. S. (2000a). Influence of neurons on lipopolysaccharide-stimulated production of nitric oxide and tumor necrosis factor-alpha by cultured glia. Brain Res. 853, 236-244. doi: 10.1016/S0006-8993 (99)02255-6

Chang, R. C., Hudson, P., Wilson, B., Liu, B., Abel, H., Hemperly, J., et al. (2000b). Immune modulatory effects of neural cell adhesion molecules on lipopolysaccharideinduced nitric oxide production by cultured glia. Mol. Brain Res. 81, 197-201. doi: 10.1016/S0169328X(00)00175-3

Chitnis, T., Imitola, J., Wang, Y., Elyaman, W., Chawla, P., Sharuk, M., et al. (2007). Elevated neuronal expression of CD200 protects Wlds mice from inflammationmediated neurodegeneration. Am. J. Pathol. 170, 1695-1712. doi: 10.2353/ajpath.2007.060677

Choi, C., and Benveniste, E. N. (2004). Fas ligand/Fas system in 
the brain: regulator of immune and apoptotic responses. Brain Res. Brain Res. Rev. 44, 65-81. doi: 10.1016/j.brainresrev.2003.08.007

Cox, F. F., Carney, D., Miller, A. M., and Lynch, M. A. (2012). CD200 fusion protein decreases microglial activation in the hippocampus of aged rats. Brain Behav. Immun. 26, 789-796. doi: 10.1016/j.bbi.2011.10.004

Cragnolini, A. B., Volosin, M., Huang, Y., and Friedman, W. J. (2012). Nerve growth factor induces cell cycle arrest of astrocytes. Dev. Neurobiol. 72, 766-776. doi: 10.1002/dneu.20981

Czopik, A. K., Bynoe, M. S., Palm, N., Raine, C. S., and Medzhitov, R. (2006). Semaphorin 7A is a negative regulator of $\mathrm{T}$ cell responses. Immunity 24, 591-600. doi: 10.1016/j.immuni.2006.03.013

Delgado, M., and Ganea, D. (2003). Neuroprotective effect of vasoactive intestinal peptide (VIP) in a mouse model of Parkinson's disease by blocking microglial activation. FASEB J. 17, 944-946.

Delgado, M., Pozo, D., and Ganea, D. (2004). The significance of vasoactive intestinal peptide in immunomodulation. Pharmacol. Rev. 56, 249-290. doi: 10.1124/pr.56.2.7

Delgado, M., Varela, N., and GonzalezRey, E. (2008). Vasoactive intestinal peptide protects against beta-amyloid induced neurodegeneration by inhibiting microglia activation at multiple levels. Glia 56, 1091-1103. doi: 10.1002/glia.20681

Färber, K., and Kettenmann. (2005). Physiology of microglial cells. Brain Res. Brain Res. Rev. 48, 133-143. doi: 10.1016/j.brainresrev.2004.12.003

Färber, K., Pannasch, U., and Kettenmann, H. (2005). Dopamine and noradrenaline control distinct functions in rodent microglial cells. Mol. Cell. Neurosci. 29, 128-138. doi: 10.1016/j.mcn.2005. 01.003

Fernandez-Martin, A., Gonzalez-Rey, E., Chorny, A., Ganea, D., and Delgado, M. (2006). Vasoactive intestinal peptide induces regulatory $\mathrm{T}$ cells during experimental autoimmune encephalomyelitis. Eur. J. Immunol. 36, 318-326. doi: 10.1002/eji.200535430

Flügel, A., Schwaiger, F. W., Neumann, H., Medana, I., Willem, M., Wekerle, H., et al. (2000). Neuronal FasL induces cell death of encephalitogenic $\mathrm{T}$ lymphocytes. Brain Pathol. 10, 353-364. doi: 10.1111/j.17503639.2000.tb00267.x
Gründemann, C., Bauer, M., Schweier, O., von Oppen, N., Lässing, U., Saudan, P., et al. (2006). Cutting edge: identification of E-cadherin as a ligand for the murine killer cell lectin-like receptor G1. J. Immunol. 176, 1311-1315.

Guo, H., Tong, N., Turner, T., Epstein, L. G., McDermott, M. P., Kilgannon, P., et al. (2000). Release of the neuronal glycoprotein ICAM-5 in serum after hypoxic-ischemic injury. Ann. Neurol. 48, 590-602.

Gyoneva, S., and Traynelis, S. F. (2013). Norepinephrine modulates the motility of resting and activated microglia via different adrenergic receptors. J. Biol. Chem. 288, 15291-15302. doi: 10.1074/jbc. M113.458901

Harrison, J. K., Jiang, Y., Chen, S., Xia, Y., Maciejewski, D., McNamara, R. K., et al. (1998). Role for neuronally derived fractalkine in mediating interactions between neurons and CX3CR1-expressing microglia. Proc. Natl. Acad. Sci. U.S.A. 95, 10896-10901. doi: 10.1073/pnas.95.18.10896

Heyen, J. R., Ye, S., Finck, B. N., and Johnson, R. W. (2000). Interleukin (IL)-10 inhibits IL-6 production in microglia by preventing activation of NF-kappaB. Mol. Brain Res. 77, 138-147. doi: 10.1016/S0169328X(00)00042-5

Hoek, R. M., Ruuls, S. R., Murphy, C. A., Wright, G. J., Goddard, R., Zurawski, S. M., et al. (2000). Down-regulation of the macrophage lineage through interaction with OX2 (CD200). Science 290, 1768-1771. doi: 10.1126/science. 290.5497 .1768

Hughes, P. M., Botham, M. S., Frentzel, S., Mir, A., and Perry, V. H. (2002). Expression of fractalkine (CX3CL1) and its receptor, CX3CR1, during acute and chronic inflammation in the rodent CNS. Glia 37, 314-327. doi: 10.1002/glia.10037

Issazadeh, S., Navikas, V., Schaub, M., Sayegh, M., and Khoury, S. (1998). Kinetics of expression of costimulatory molecules and their ligands in murine relapsing experimental autoimmune encephalomyelitis in vivo. J. Immunol. 161, 1104-1112.

Ito, M., Maruyama, T., Saito, N., Koganei, S., Yamamoto, K., and Matsumoto, N. (2006). Killer cell lectin-like receptor G1 binds three members of the classical cadherin family to inhibit NK cell cytotoxicity. J. Exp. Med. 203, 289-295. doi: 10.1084/jem.20051986

Koning, N., Bö, L., Hoek, R. M., and Huitinga, I. (2007).
Downregulation of macrophage inhibitory molecules in multiple sclerosis lesions. Ann. Neurol. 62, 504-514. doi: 10.1002/ana.21220

Koning, N., Swaab, D. F., Hoek, R. M., and Huitinga, I. (2009). Distribution of the immune inhibitory molecules CD200 and CD200R in the normal central nervous system and multiple sclerosis lesions suggests neuronglia and glia-glia interactions. J. Neuropathol. Exp. Neurol. 68, 159-167. doi: 10.1097/NEN.0b013 e3181964113

Krushel, L. A., Sporns, O. Cunningham, B. A., Crossin, K. L., and Edelman, G. M. (1995). Neural cell adhesion molecule (N-CAM) inhibits astrocyte proliferation after injury to different regions of the adult rat brain. Proc. Natl. Acad. Sci. U.S.A. 92, 4323-4327. doi: 10.1073/pnas.92.10.4323

Krushel, L. A., Tai, M. H., Cunningham, B. A., Edelman, G. M., and Crossin, K. L. (1998). Neural cell adhesion molecule (N-CAM) domains and intracellular signaling pathways involved in the inhibition of astrocyte proliferation. Proc. Natl. Acad. Sci. U.S.A. 95, 2592-2596. doi: 10.1073/pnas.95.5.2592

Kuhn, S. A., van Landeghem, F. K., Zacharias, R., Färber, K., Rappert, A., Pavlovic, S., et al. (2004). Microglia express GABA(B) receptors to modulate interleukin release. Mol. Cell. Neurosci. 25, 312-322. doi: 10.1016/j.mcn.2003.10.023

Lamy, L., Foussat, A., Brown, E. J. Bornstein, P., Ticchioni, M., and Bernard, A. (2007). Interactions between $\mathrm{CD} 47$ and thrombospondin reduce inflammation. J. Immunol. 178, 5930-5939.

Laudiero, L. B., Aloe, L., LeviMontalcini, R., Buttinelli, C., Schilter, D., Gillessen, S., et al. (1992). Multiple sclerosis patients express increased levels of betanerve growth factor in cerebrospinal fluid. Neurosci. Lett. 147, 9-12. doi: 10.1016/0304-3940(92)90762-V

Lepelletier, Y., Moura, I. C., HadjSlimane, R., Renand, A., Fiorentino, S., Baude, C., et al. (2006). Immunosuppressive role of semaphoring-3A on $\mathrm{T}$ cell proliferation is mediated by inhibition of actin cytoskeleton reorganization. Eur. J. Immunol. 36, 1782-1793. doi: 10.1002/eji.200535601

Lindsberg, P. J., Launes, J., Tian, L., Välimaa, H., Subramanian, V., Sirén, J., et al. (2002). Release of soluble ICAM-5, a neuronal adhesion molecule, in acute encephalitis.
Neurology 58, 446-451. doi: 10.1212/WNL.58.3.446

Liu, Y., Teige, I., Birnir, B., and Issazadeh-Navikas, S. (2006). Neuron-mediated generation of regulatory $\mathrm{T}$ cells from encephalitogenic $\mathrm{T}$ cells suppresses EAE. Nat. Med. 12, 518-525. doi: 10.1038/nm1402

Lyons, A., McQuillan, K., Deighan, B. F., O'Reilly, J. A., Downer, E. J., Murphy, A. C., et al. (2009). Decreased neuronal CD200 expression in IL-4 deficient mice result in increased neuroinflammation in response to lipopolysaccharide. Brain Behav. Immun. 23, 1020-1027. doi: 10.1016/j.bbi.2009. 05.060

Majed, H. H., Chandran, S., Niclou, S. P., Nicholas, R. S., Wilkins, A., Wing, M. G., et al. (2006). A novel role for Sema-3A in neuroprotection from injury mediated by activated microglia. J. Neurosci. 26, 1730-1738. doi: 10.1523/JNEUROSCI.0702-05.2006

Medana, I., Li, Z., Flügel, A., Tschopp, J., Wekerle, H., and Neumann, H. (2001). Fas ligand (CD95L) protects neurons against perforin-mediated $\mathrm{T}$ lymphocyte cytotoxicity. J. Immunol. 167, 674-681.

Mizuno, T., Kawanokuchi, J., Numata, K., and Suzumura, A. (2003). Production and neuroprotective functions of fractalkine in the central nervous system. Brain Res. 979, 65-70. doi: 10.1016/S00068993(03)02867-1

Mizuno, T., Yoshihara, Y., Kagamiyama, H., Ohsawa, K., Imai, Y., Kohsaka, S., et al. (1999). Neuronal adhesion molecule telencephalin induces rapid cell spreading of microglia. Brain Res. 849, 58-66. doi: 10.1016/S0006-8993(99)01984-8

Moretti, S., Procopio, A., Lazzarini, R., Rippo, M. R., Testa, R., Marra, M., et al. (2008). Semaphorin3A signaling controls Fas (CD95)mediated apoptosis by promoting Fas translocation into lipid rafts. Blood 111, 2290-2299. doi: 10.1182/blood-2007-06-096529

Mott, R. T., Ait-Ghezala, G., Town, T., Mori, T., Vendrame, M., Zeng, J., et al. (2004). Neuronal expression of CD22: novel mechanism for inhibiting microglial proinflammatory cytokine production. Glia 46 369-379. doi: 10.1002/glia.20009

Neumann, H., Misgeld, T., Matsumuro, K., and Wekerle, H. (1998). Neurotrophins inhibit major histocompatibility class II inducibility of microglia: involvement of the p75 neurotrophin receptor. Proc. Natl. 
Acad. Sci. U.S.A. 95, 5779-5784. doi: $10.1073 /$ pnas. 95.10 .5779

Noda, M., Doi, Y., Liang, J., Kawanokuchi, J., Sonobe, Y., Takeuchi, H., et al. (2011). Fractalkine attenuates excitoneurotoxicity via microglial clearance of damaged neurons and antioxidant enzyme heme oxygenase-1 expression. J. Biol. Chem. 286, 2308-2319. doi: 10.1074/jbc.M110.169839

Pratt, B. M., and McPherson, J. M. (1997). TGF-beta in the central nervous system: potential roles in ischemic injury and neurodegenerative diseases. Cytokine Growth Factor Rev. 8, 267-292. doi: 10.1016/S1359-6101(97)00018-X

Reinhold, M. I., Lindberg, F. P., Plas, D., Reynolds, S., Peters, M. G., and Brown, E. J. (1995). In vivo expression of alternatively spliced forms of integrin-associated protein (CD47). J. Cell Sci. 108, 3419-3425.

Rijkers, E. S., de Ruiter, T., Baridi, A., Veninga, H., Hoek, R. M., and Meyaard, L. (2008). The inhibitory CD200R is differentially expressed on human and mouse $\mathrm{T}$ and $\mathrm{B}$ lymphocytes. Mol. Immunol. 45, 1126-1135. doi: 10.1016/j.molimm. 2007.07.013

Roney, K., Holl, E., and Ting, J. (2013). Immune plexins and semaphorins: old proteins, new immune functions. Protein Cell 4, 17-26. doi: 10.1007/s13238-012-2108-4

Saenz, B., Pérez-H, J., Chavarría, A. (2010). Regulatory T cells in central nervous system: in health and disease. Cent. Nerv. Syst. Agents Med. Chem. 10, 326-336. doi: 10.2174/187152410793429674

Sawada, M., Suzumura, A., Hosoya, H., Marunouchi, T., and Nagatsu, T. (1999). Interleukin-10 inhibits both production of cytokines and expression of cytokine receptors in microglia. J. Neurochem. 72, 1466-1471. doi: 10.1046/j.14714159.1999.721466.x

Simonini, M. V., Polak, P. E., Sharp, A., McGuire, S., Galea, E., and Feinstein, D. L. (2010). Increasing CNS noradrenaline reduces
EAE severity. J. Neuroimmune Pharmacol. 5, 252-259. doi: 10.1007/s11481-009-9182-2

Smith, R. E., Patel, V., Seatter, S. D., Deehan, M. R., Brown, M H., Brooke, G. P., et al. (2003). A novel MyD-1 (SIRP-1alpha) signaling pathway that inhibits LPSinduced TNFalpha production by monocytes. Blood 102, 2532-2540. doi: 10.1182/blood-2002-11-3596

Sporns, O., Edelman, G. M., and Crossin, K. L. (1995). The neural cell adhesion molecule (N-CAM) inhibits proliferation in primary cultures of rat astrocytes. Proc. Natl. Acad. Sci. U.S.A. 92, 542-546. doi 10.1073/pnas.92.2.542

Strle, K., Zhou, J., Shen, W. H., Broussard, S. R., Johnson, R W., Freund, G. G., et al. (2001). Interleukin-10 in the brain. Crit. Rev. Immunol. 21, 427-449. doi: 10.1615/CritRevImmunol.v21.i5.20 Suzumura, A., Sawada, M., Yamamoto, H., Marunouchi, T. (1993). Transforming growth factorbeta suppresses activation and proliferation of microglia in vitro. J. Immunol. 151, 2150-2218.

Szelényi, J. (2001). Cytokines and the central nervous system. Brain Res. Bull. 54, 329-338. doi: 10.1016/S0361-9230(01)00428-2

Szelényi, J., and Vizi, E. S. (2007). The catecholamine cytokine balance: interaction between the brain and the immune system. Ann. N.Y. Acad. Sci. 1113, 311-324. doi: 10.1196/annals.1391.026

Tabakman, R., Lecht, S., Sephanova, S., Arien-Zaray, H., and Lazarovici, P. (2004). Interactions between the cells of the immune and nervous system: neurotrophins as neuroprotection mediators in CNS injury. Prog. Brain Res. 146 387-401. doi: 10.1016/S0079-6123 (03)46024-X

Tan, J., Town, T., and Mullan, M. (2000). CD45 inhibits CD40Linduced microglial activation via negative regulation of the Src/p44/42 MAPK pathway. J. Biol. Chem. 275, 37224-37231. doi 10.1074/jbc.M002006200
Tian, L., Kilgannon, P., Yoshihara, Y., Mori, K., Gallatin, W. M., Carpén, O., et al. (2000). Binding of $\mathrm{T}$ lymphocytes to hippocampal neurons through ICAM-5 (telencephalin) and characterization of its interaction with the leukocyte integrin CD11a/CD18. Eur. J. Immunol. 30, 810-818.

Tian, L., Lappalainen, J., Autero, M. Hänninen, S., Rauvala, H., and Gahmberg, C. G. (2008). Shedded neuronal ICAM-5 suppresses T-cell activation. Blood 111, 3615-3625. doi: 10.1182/blood-2007-09-111179

Tian, L., Rauvala, H., and Gahmberg, C. G. (2009). Neuronal regulation of immune responses in the central nervous system. Trends Immunol. 30, 91-99. doi: 10.1016/j.it.2008.11.002

Tzeng, S. F., and Huang, H. Y (2003). Downregulation of inducible nitric oxide synthetase by neurotrophin-3 in microglia. J. Cell Biochem. 90, 227-233. doi: 10.1002/ jcb. 10658

Tzeng, S. F., Huang, H. Y., Lee, T. I. and Jwo, J. K. (2005). Inhibition of lipopolysaccharide-induced microglial activation by preexposure to neurotrophin-3. J. Neurosci. Res. 81, 666-676. doi: 10.1002/jnr. 20586

Walker, D. G., Dalsing-Hernandez, J. E., Campbell, N. A., and Lue, L. F. (2009). Decreased expression of CD200 and CD200 receptor in Alzheimer's disease: a potential mechanism leading to chronic inflammation. Exp. Neurol. 215, 5-19. doi: 10.1016/j.expneurol. 2008.09.003

Wei, R., and Jonakait, G. M. (1999) Neurotrophins and the antiinflammatory agents interleukin 4(IL-4), IL-10, IL-11 and transforming growth factor-betal (TGF-betal) down-regulate $\mathrm{T}$ cel costimulatory molecules $\mathrm{B} 7$ and CD40 on cultured rat microglia. J. Neuroimmunol. 95, 8-18. doi: 10.1016/S0165-5728(98)00248-3

Zhang, S., Cherwinski, H., Sedgwick, J. D., and Phillips, J. H. (2004). Molecular mechanisms of CD200 inhibition of mast cell activation. J. Immunol. 173, 6786-6793.

Zhang, S., Wang, X. J., Tian, L. P., Pan, J., Lu, G. Q., Zhang, Y. J., et al. (2011). CD200-CD200R dysfunction exacerbates microglial activation and dopaminergic neurodegeneration in a rat model of Parkinson's disease. J. Neuroinflammation 8, 154. doi: 10.1186/1742-2094-8-154

Zhu, Y., Hou, H., Nikolic, W. V., Ehrhart, J., Rrapo, E., Bickford, P., et al. (2008). CD45RB is a novel molecular therapeutic target to inhibit Abeta peptide-induced microglial MAPK activation. PLoS ONE 3:e2135. doi: 10.1371/journal. pone.0002135

Zujovic, V., Benavides, J., Vigé, X., Carter, C., and Taupin, V. (2000). Fractalkine modulates TNF-alpha secretion and neurotoxicity induced by microglial activation. Glia 29 , 305-315.

Conflict of Interest Statement: The authors declare that the research was conducted in the absence of any commercial or financial relationships that could be construed as a potential conflict of interest.

Received: 07 May 2013; accepted: 07 August 2013; published online: 02 September 2013.

Citation: Chavarría A and Cárdenas $G$ (2013) Neuronal influence behind the central nervous system regulation of the immune cells. Front. Integr. Neurosci. 7:64. doi: 10.3389/fnint.2013.00064

This article was submitted to the journal Frontiers in Integrative Neuroscience.

Copyright (C) 2013 Chavarría and Cárdenas. This is an open-access article distributed under the terms of the Creative Commons Attribution License (CC BY). The use, distribution or reproduction in other forums is permitted, provided the original author(s) or licensor are credited and that the original publication in this journal is cited, in accordance with accepted academic practice. No use, distribution or reproduction is permitted which does not comply with these terms. 